\title{
Entamoeba hartmanni
}

National Cancer Institute

\section{Source}

National Cancer Institute. Entamoeba hartmanni. NCI Thesaurus. Code C122296.

A species of commensal parasite in the class Archamoebae. E. hartmanni is considered nonpathog enic. Cysts are transmitted through contaminated food or water. 